\title{
Bibliometric analysis of Asian Pacific Journal of Tropical Medicine from 2008 to 2019
}

\author{
Taha Hussein Musa ${ }^{1}$, Abdelaziz Adam Idriss Arbab ${ }^{2}$, Hassan Hussein Musa ${ }^{3}$ \\ ${ }^{1,2}$ Biomedical Research Institute, Darfur College, Sudan \\ ${ }^{2}$ Key Laboratory of Animal Genetics and Breeding and Molecular Design of Jiangsu Province, \\ Yangzhou University, China \\ ${ }^{3}$ Department of Medical Microbiology, Faculty of Medical Laboratory Sciences, University of Khartoum, Sudan
}

\begin{tabular}{|c|c|}
\hline Article Info & ABSTRACT \\
\hline Article history: & The purpose of the study is to assess the scientific research productions \\
\hline Received Mar 2, 2020 & $\begin{array}{l}\text { in Asian Pacific Journal of Tropical Medicine (APJTM) from its first issue } \\
\text { un to Dec 2019 We used the Web of Science Core Collection }\end{array}$ \\
\hline Revised Apr 24, 2020 & (SCI-EXPANDED, SSCI) to extract the relevant documents. \\
\hline Accepted May 7, 2020 & $\begin{array}{l}\text { Additionally, the data analysis using ORIGIN PRO 2018, HistCite, } \\
\text { bibliometrix R-package, and VOSviewer. Var1.6.6. A total of }\end{array}$ \\
\hline Keywords: & $\begin{array}{l}2,137 \text { publications of APJTM. A total of } 2,136 \text { documents were retrieved, } \\
\text { with received } 13956 \text { citations, with an average mean } 6.63 \text { citations per }\end{array}$ \\
\hline APJTM & article, an h-index of 38 . The most frequently occurring keywords in this \\
\hline Bibliometric & anopheles stephesi and inflammation. The study provided the comprehensive \\
\hline Cited documents & and general overview for APJTM journal over its history from the first issue \\
\hline Journal & up-to-date. Moreover, the findings provide an insight into the frequency \\
\hline VOSviewer & $\begin{array}{l}\text { of citations for top-cited articles published in APJTM as well as the quality } \\
\text { of the works, journals, trends of publications steering in APJTM. }\end{array}$ \\
\hline
\end{tabular}

This is an open access article under the CC BY-SA license.

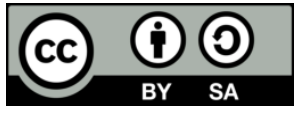

\section{Corresponding Author:}

Taha Hussein Musa, Biomedical Research Institute, Darfur College, Sudan. Email: taha.hm99@yahoo.com

\section{INTRODUCTION}

The Journal of Asian Pacific Journal of Tropical Medicine (APJTM) is a leading international journal in the field of public, environmental and occupational health and tropical medicine created in 1993. The journal is indexed in the DOAJ, EMBASE/ Excerpta Medica, Index Copernicus, Science Citation Index Expanded, SCOPUS, and journal citation reports of the web of science; in 2018 edition, it has an impact factor of 1.772. In 2008, it began as a quarterly journal, and in 2009, it became a bimonthly journal. Undoubtedly, the inclusion of any journal into public reported data databases increases exponentially the citation rate and the published documents were being visible to a wide-ranging audience as previously reported in other medical journal [1,2].

The APJTM International Standard Serial Number (ISSN) 1955-7645. Sponsored by Institute of Tropical Disease, Hainan Medical University, China. The APJTM is devoted to the academic publications, communicating platform for international doctors, medical scientists, allied health scientists, public health employees, particularly those of the Asia-Pacific area and throughout the world. Provides extraordinary contribution in the field of scientific research production and set up an academic communication platform for Chinese and the rest of the world precisely in tropical medicine and other related fields as open access 
journal, when it began to publish and it first issues published in January 25, 2018, till transferred back to the society in 2018. Throughout the monthly peer-reviewing process. Accordingly, in 2019. APJTM became 11 years old. Moreover, the scientific research production of APJTM in this field and publication output is unknown. Motivated by this event of continuous producing articles in the field of tropical medicine, in the whole country, and worldwide.

Therefore, for better understanding of the growth and development of the journal, bibliometric studies have been a massively useful tool to the academic community in identifying most productive authors and potential publications. Furthermore, it helps scientist in determining the highly cited documents, leading authors, geographical distribution, countries or academic institutions, funding agency, and other significant details of any specific literature [3]. Hence, the APJTM being indexed in WOS databases in 2008. Then, it essential to conduct a bibliometric study to provide a better understanding of the journal aspect and provides insight into overview that goes far beyond the scope of APJTM during the past years.

\section{RESEARCH METHOD}

\subsection{Study design and data search}

The documents published in APJTM were identified using the advanced search option. The articles published from 2008 till Dec 2019. The following terms were searched: Publication name: ("Asian Pacific Journal of Tropical Medicine") In Expanded (SCI-EXPANDED) and Social Sciences Citation Index (SSCI) using the applications "Web of Science" (WOS) databases (Clarivate Analytics, USA) to achieve the purpose of this study. The search was performed on 3rd Feb 2020 for articles published from 2008-2019.

\subsection{Inclusion criteria}

All document types, including articles, reviews, editorial materials, meeting abstract, and letter to the editor written and published in English up until the end of 2019 were included. Ethical approval was not required in this study because no human subjects were involved in this study.

\subsection{Data extraction}

Initially, the search strategies filtering resulted in 2,137 documents in WOS form APJTM. All the information was exported in CSV and plain text format for further analysis.

\subsection{Bibliometric indicators}

The paper covers the bibliometric analyses presenting the year-wise distribution of published documents, category-wise distribution of type of documents, Institutions or countries-wise distribution of contributions, prolific authors, authors affiliations, author keywords, article citation frequency reports, international collaborations, and geographical distribution of the publications.

\subsection{Statistical analysis}

All data were analyzed using ORIGIN PRO 2018, 2018, HistCite ${ }^{\mathrm{TM}}$ [4], and VOSviewer.Var1.6.6 (Leiden University, Leiden, Te Netherlands) [5]. The program is freely available at (www.vosviewer.com) was used to construct the collaborative networks analysis between the authors and frequently occurring authors' keywords or countries by using bibliometric analysis [6].

\section{RESULTS AND DISCUSSIONS}

\subsection{Types of retrieved documents}

A total of 2137 documents were retrieved, with 13951 total global citations. The highest number of retrieved documents in APJTM were research articles $(n=1,912 ; 89.5 \%)$, and review articles $(129 ; 6 \%)$. Other types of retrieved documents include editorial material $(n=42 ; 2 \%)$, meeting abstract, $(n=36 ; 1.7 \%)$, and letter $(\mathrm{n}=17 ; 0.0 \%)$. Table 1 presents the type of retrieved documents.

\subsection{Annual publications}

The number of publications remained close to 50-100 between 2008 and 2009. The growth in publications was reached more than 200 in the year 2010, 2011, 2014, and 2016. The maximum number of publications was 294 publications recorded in 2014 as shown in Figure 1. 
Table 1. Type of retrieved documents $(\mathrm{N}=2,136)$

\begin{tabular}{cccc}
\hline Type of document & Recs & Percent & TGCS \\
\hline Article & 1912 & 89.5 & 12529 \\
Review & 129 & 6.0 & 1244 \\
Editorial material & 42 & 2.0 & 71 \\
Meeting abstract & 36 & 1.7 & 2 \\
Letter & 17 & 0. & 105 \\
\hline TGCS: Total global citations score
\end{tabular}

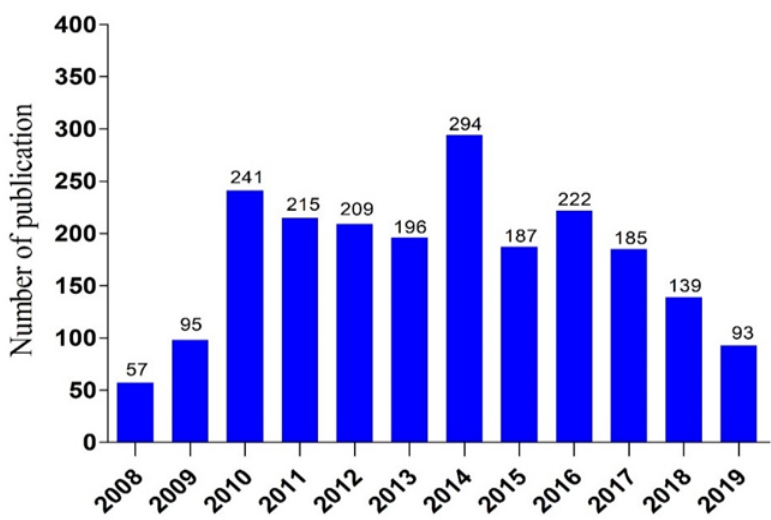

Figure 1. Annual publications in APJTM during 2008-2019

\subsection{Annual citations}

The retrieved documents received 13956 citations and had an average h-index of 38, an average of citation per documents 6.53, excluding self-citations. Meanwhile, the peak of the total cited document increased in the year 2010-2016, and the most times cited per paper is (2466) in the year 2011. Figure 2 shows the annual distribution of total cited documents and average citation sore.

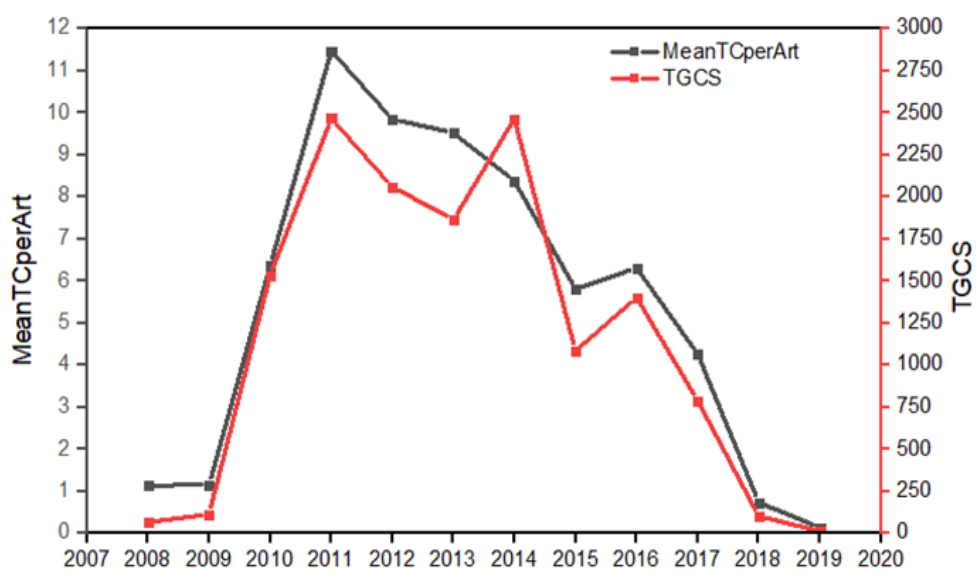

Figure 2. Annual distribution of total cited documents and average cited document per an article in n APJTM

\subsection{Most productive institutions and countries}

The results of analysis revealed that Hainan Medical University in China turned out as the top productive institution contributed by the results of the analysis $(n=78 ; 3.7 \%)$, with 237 cited score, followed by other institutions from Tehran University of Medical Sciences in Iran ( $n=47 ; 2.2 \%)$, with 425 cited score. A closer look at Table 2 revealed that the top 10 most productive countries from retrieved documents including China had greatest number of documents $(\mathrm{n}=615 ; 28.8 \%)$, followed by India $(n=487 ; 22.8 \%)$, Nigeria $(n=168 ; 7.9 \%)$, and Iran $(n=148 ; 6.9 \%)$. Table 2 presents the top ten cited institutions and countries published paper in APJTM. 
Table 2. Top ten cited institutions and countries that published papers in APJTM

\begin{tabular}{|c|c|c|c|c|c|}
\hline Institutions & $\mathrm{N}(\%)$ & TGCS (R) & Country & $\mathrm{N}(\%)$ & TGCS \\
\hline Hainan Medical University & $78(3.7)$ & $237(3)$ & China & $615(28.8)$ & $2981(2)$ \\
\hline Tehran University of Medical Sciences & $47(2.2)$ & $425(2)$ & India & $487(22.8)$ & $4673(1)$ \\
\hline University of Nigeria & $37(1.7)$ & $191(5)$ & Nigeria & $168(7.9)$ & $666(4)$ \\
\hline Hainan Medical College & $35(1.6)$ & $117(8)$ & Iran & $148(6.9)$ & $1343(3)$ \\
\hline Mahidol University & $35(1.6)$ & $228(4)$ & Thailand & $103(4.8)$ & $607(5)$ \\
\hline Zhengzhou University & $33(1.5)$ & $147(6)$ & Malaysia & $81(3.8)$ & $575(6)$ \\
\hline Annamalai University & $32(1.5)$ & $623(1)$ & Egypt & $66(3.1)$ & $398(8)$ \\
\hline Central South University & $28(1.3)$ & $113(9)$ & Pakistan & $62(2.9)$ & $426(7)$ \\
\hline National research Center & $26(1.2)$ & $131(7)$ & USA & $57(2.7)$ & 191(10) \\
\hline University of Port Harcourt & $23(1.1)$ & $55(10)$ & South Korea & $46(2.2)$ & $408(9)$ \\
\hline
\end{tabular}

TGCS: Total global cited score

\subsection{Top-10 authors' analysis}

Our study showed that the most top-10 active authors contributing documents in APJTM were in China in addition to authors in Australia, India and Iran. Of top 10 most prolific authors, are professor Wiwanitkit V, from Hainan Medical University, Hainan, China 20 (0.9\%), followed by Professor Chen J from the Shihezi University College of Animal Science and Technol, Xinjiang, China 15(0.7\%). Table 3 shows the result of the top 10 prolific authors contributing document to APJTM.

Table 3. Top 10 prolific authors contributing documents to APJTM

\begin{tabular}{|c|c|c|c|c|c|c|}
\hline Rank & Author & $\begin{array}{l}\text { Number of } \\
\text { articles } \\
(\%)\end{array}$ & $\begin{array}{l}\text { Number of } \\
\text { Times Cited } \\
\text { (R) }\end{array}$ & $\begin{array}{l}\text { Average } \\
\text { citations per } \\
\text { item }(\mathrm{R})\end{array}$ & $\begin{array}{l}\text { h-index } \\
\text { (R) }\end{array}$ & $\begin{array}{c}\text { Affiliation } \\
\text { (Institution, Country) }\end{array}$ \\
\hline 1 & Wiwanitkit V & $20(0.9)$ & $105(3)$ & $5.25(8)$ & $4(5)$ & Hainan Medical University, Hainan, China \\
\hline 2 & Chen $\mathrm{J}$ & $15(0.7)$ & $65(10)$ & $4.33(10)$ & $5(4)$ & $\begin{array}{l}\text { Shihezi University College of Animal Science } \\
\text { and Technol, Xinjiang, China }\end{array}$ \\
\hline 3 & Zhang L & $15(0.7)$ & $102(4)$ & $6.8(5)$ & $5(4)$ & $\begin{array}{c}\text { Western Sydney University School Science } \\
\text { and Health Penrith, NSW, Australia }\end{array}$ \\
\hline 4 & $\mathrm{Li} \mathrm{Y}$ & $14(0.7)$ & $81(7)$ & $5.79(7)$ & $6(3)$ & $\begin{array}{l}\text { University of Southern Queensland, Faculty of } \\
\text { Health Engineering and Science, Toowoomba, } \\
\text { QLD, Australia }\end{array}$ \\
\hline 5 & Liu Y & $14(0.7)$ & $72(8)$ & $5.14(9)$ & $5(4)$ & $\begin{array}{c}\text { Sichuan University College Life Science } \\
\text { Chengdu, Sichuan, China }\end{array}$ \\
\hline 6 & Zhang Y & $14(0.7)$ & $68(9)$ & $4.86(6)$ & $6(3)$ & Nanjing Chest Hosp Nanjing, Jiangsu, China \\
\hline 7 & Chandra $\mathrm{G}$ & $11(0.5)$ & $81(6)$ & $7.36(4)$ & $7(2)$ & $\begin{array}{l}\text { University of Burdwan Dept Zool Burdwan, } \\
\text { W BENGAL, India }\end{array}$ \\
\hline 8 & Bahmani M & $10(0.5)$ & $368(1)$ & $36.8(1)$ & $9(1)$ & $\begin{array}{c}\text { Ilam University Medical Science, } \\
\text { Biotechnology and Med Plants Research Centr, } \\
\text { Ilam, Iran }\end{array}$ \\
\hline 9 & Chen Y & $10(0.5)$ & $106(2)$ & $10.6(2)$ & $5(4)$ & $\begin{array}{c}\text { Sichuan University West China University } \\
\text { Hospital 2, Chengdu, China }\end{array}$ \\
\hline 10 & Hassan V & $10(0.5)$ & $92(5)$ & $9.2(3)$ & $6(3)$ & $\begin{array}{c}\text { Tehran University of Medical Sciences School } \\
\text { of Public Health, Tehran, Iran }\end{array}$ \\
\hline
\end{tabular}

\subsection{Top ten cited articles}

The top 10 documents in APJTM and their citation frequency and the average of cited documents are listed in table [7-16]. Singh N et al. wrote the most high-ranking article in the journal, with two hundred and thirteen citations for the article entitled "Leishmaniasis: Current status of available drugs and new potential drug targets" [7], followed by paper authored by DebMandal M. with one hundred and forty-two citation [8], and Gnanadesigan M, et al. with eighty-four citations score [9]. The top cited documents are shown in Table 4.

\subsection{Co-author network collaboration and countries}

Figure 3 present the collaboration network of the documents published by APJTM during the period 2008-2019. Node size is proportional to the number of documents published by each country. Likewise, lines thickness of the link between any two countries is revealing the extent of co-authorships (collaboration), respectively. Undoubtedly, the international researchers who collaborated with people republic of China researchers were from India, Nigeria, Egypt, and the United States. 
Table 4. The top 10 cited document on APJTM



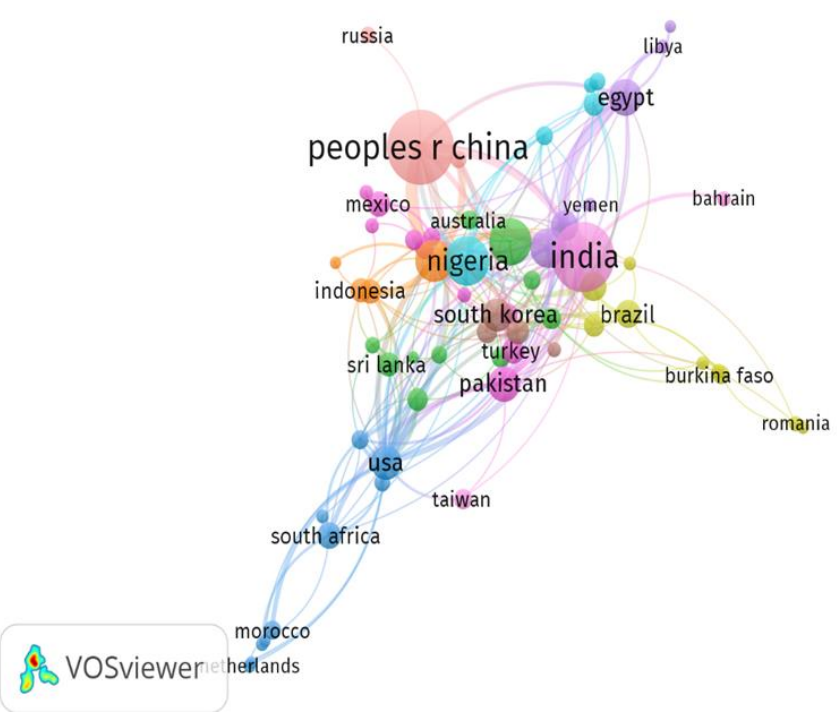

Figure 3. Co-author network collaboration and countries based on the total number of documents published by APJTM between 2008-2019

\subsection{Word co-occurrence network between word and documents}

APJTM has published approximately 6,522 keywords. A total of 3179 different keywords present in the titles and abstracts documents published between 2008-2013, with a minimum of 5 selected keywords, which resulted in 97 keywords met the threshold were analysed in order to establish the co-occurrence network, using VOSviewer to generate clusters that can be associated to research topics published in APJTM. The colours used indicate words within the same topic cluster. Figure 4 a show a total of 3343 keywords presented in APJTM during the period 2008-2013, distinguishing in 7 clusters with link strength 391. Instead, Figure $4 \mathrm{~B}$ shows the terms with high co-occurrence frequencies keywords in the period 2014-2019. This network forms eight clusters with different colour represent groups of terms that are strongly related to each other. Figure $4 \mathrm{~A}$ and B presented the Word co-occurrence network built using words of documents published between 2008-2013, and documents published between 2014-2019. 


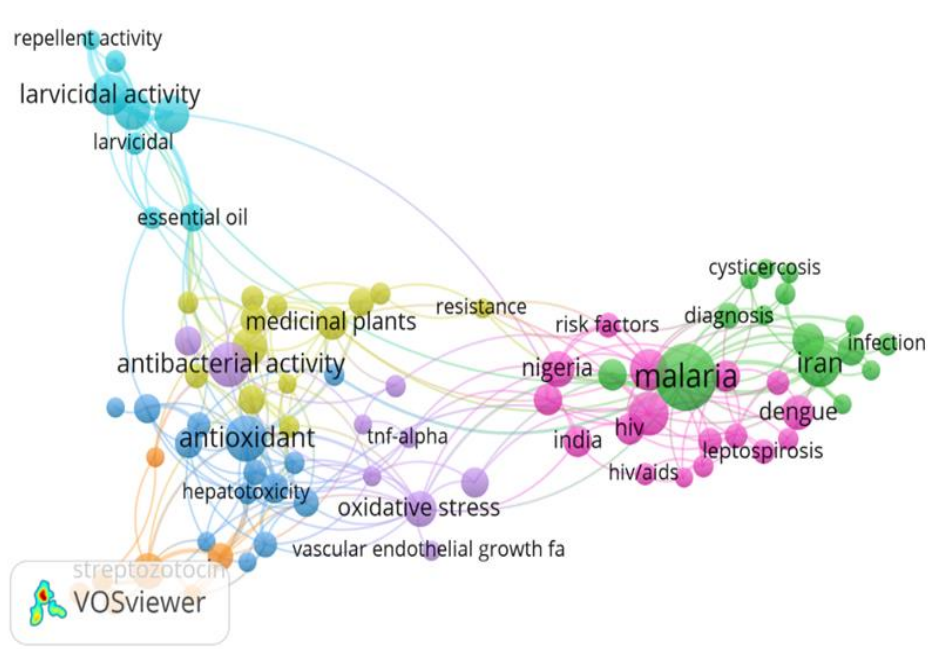

(a)

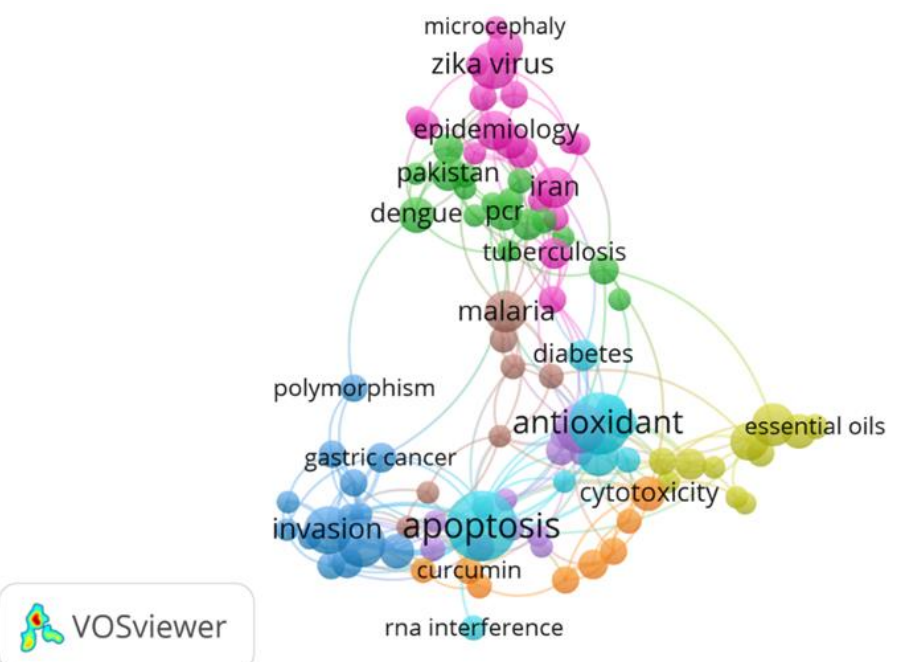

(b)

Figure 4. Word co-occurrence network built using words of (a) documents published between 2008-2013 (b) documents published between 2014-2019

\subsection{Visualization of co-authorship and authors}

Co-authorship among authors in APJTM research depicted using a network visualization map, our analysis shows among 8392 co-authorship and authors document, a minimum three authors were selected, and 380 met the threshold were visualized in 6 clusters with the link strength 407 . The collaboration was observed between any two authors. Figure 5 shows the network visualization of co-author and author collaborations.

Although many bibliometric analysis have been conducted globally as a tool in journal evaluation, and better [17-18] understanding the significance of research output in the field of Medical Sciences [1, 2], using bibliometric techniques that can help in construct, analyze, and data visualization approaches [19] for specific scientific journals [20-23]. The purpose of this study is to bibliometrically assess APJTM characteristics since it began being indexed by WOS database in early of 2008, the time at which the journal only published three issues per year. Moreover, move to 6 issues in 2009, and monthly issues distributed annually caused a noticeable growth in the total number of published papers which has not affected the quality of its work. In fact, since 2018 JIPH has been ranked among the second quartile journals in two different disciplines: "Public, environmental and occupational health" with rank (106/186) and "Tropical medicine" with rank (11/21). In past studies, highly cited papers have been preserved as one of many phenomena to validate superior research of a country in the global research field [24, 25]. 
A study published by reference [25] indicated that the highly cited papers are often considered of great importance for sustaining the status of a research institution, show intensive international collaborations between researchers based on the size of publishing countries [25]. Thus, papers or documents are the most influential one to receive a number of citations than other papers of lesser efficacy [26]. Our study finding shows that the full research article and review paper had obtained more citation score. This finding similar to what has been published $[2,27]$ which shows that the ratio of articles and reviews were high. From an institutional and countries perspective, four out ten of the Institutions are from China (Hainan Medical University, Hainan Medical College, Zhengzhou University, and Central South University) were contributed 174 documents between 2008-2019. Further analysis of their contribution to APJTM showed that 615 (28.8) of documents were published by researchers from China only, followed by India 487 (22.8). In contrast, the other three countries include Nigeria 168 (7.9), Iran 148 (6.9) and Thailand 103 (4.8). The co-occurrence networks illustrated a slight shift of research document in APJTM between the year 2008-2013, as shown in 7 different clusters. Unquestionably, more eight clusters were presented during the published documents by APJTM during the year 2014-2019 showing quite different keywords during this period; therefore, it is necessary to establish rules to prevent and control strategies of disease and promote public health.

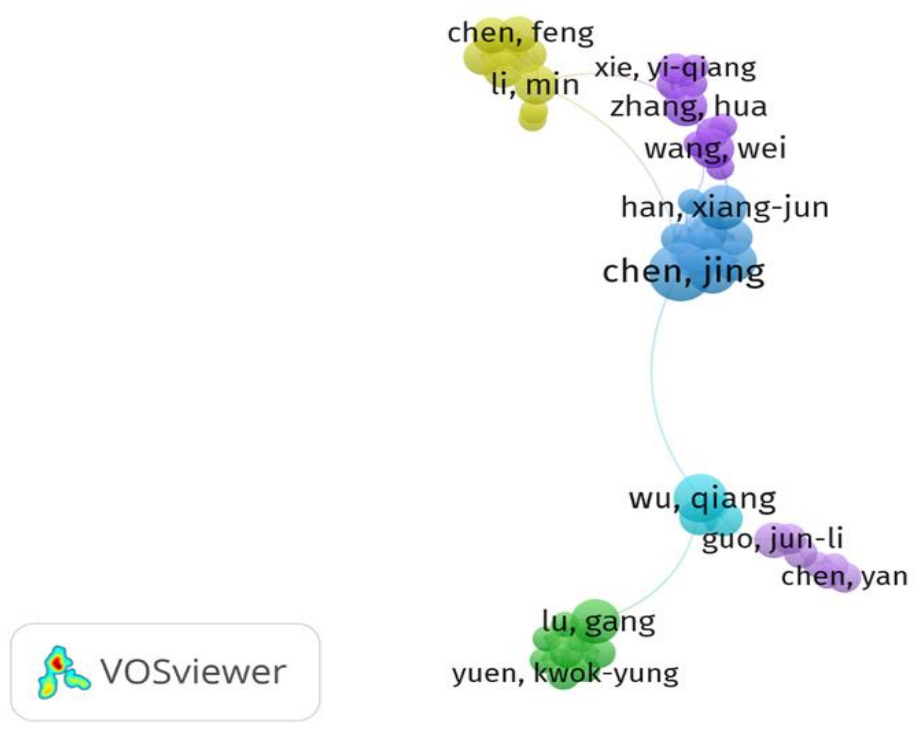

Figure 5. Network visualization of co-author and author collaborations with a minimum frequency of 3 times

\section{CONCLUSION}

This first bibliometric study of its kind identified that the monthly published articles and citation in the APJTM has increased between 2008-2019. Bibliometric studies techniques can help to identify journal citation behaviour and trends, total citation score, cited articles, most productive authors, productive institutions and countries and can help to identify possible research problems and challenges. In addition, we assess the collaborations, and word co-occurrence networks analysis, and observed that APJTM could increase its impact factor and influence the research circle in the coming future.

\section{ACKNOWLEDGEMENTS}

The authors would like to thank the library of Southeast University for giving the opportunities to access most recent information sources such as Web of Science (WOS) database.

\section{REFERENCES}

[1] Ibrahim, M., Jan, S.U., "Bibliometric Analysis of the Journal of Pakistan Medical Association form 2009 to 2013," J Pak Med Assoc., vol. 65, no. 9, pp. 978-983, 2015.

[2] Krauskopf, E., "A bibliometric analysis of the Journal of Infection and Public Health: 2008-2016," J. Infect Public Health, vol. 11, no. 2, pp. 224-229, 2018. 
[3] Garg, K.C., Anjana AK., "Journal of intellectual property rights: A bibliometric study," Desidoc, J Libr Inf Technol., vol. 34, no. 1, pp. 66-73, 2014.

[4] VanEck, N.J, Waltman, L., "Visualizing Bibliometric Networks," In Meas. Sch. Impact, pp. 285-320, sep. 2014.

[5] Danitta wong, "VOSviewer : visualizing scientific landscape," Journal Technical Services Quarterly, vol. 35, no. 2, pp. 219-220, 2018.

[6] Ellegaard,O., Wallin, JA., "The bibliometric analysis of scholarly production: How great is the impact?," Scientometrics vol. 105, no. 3, pp. 1809-1831, Jul 2015.

[7] Singh,N., et al., "Leishmaniasis: Current status of available drugs and new potential drug targets," Asian Pac J Trop Med., vol. 5, no. 6, pp. 485-497, 2012.

[8] DebMandal, M., Mandal, S., "Coconut (Cocos nucifera L.: Arecaceae): In health promotion and disease prevention," Asian Pac J Trop Med., vol. 4, no. 3, pp. 241-247, 2011.

[9] Gnanadesigan, M.,et al., "Biosynthesis of silver nanoparticles by using mangrove plant extract and their potential mosquito larvicidal property," Asian Pac J Trop Med., vol. 4, no. 10, pp. 799-803, 2011.

[10] Bahmani M, et al., "Ethnobotanical study of medicinal plants used in the management of diabetes mellitus in the Urmia, Northwest Iran,” Asian Pac J Trop Med., vol. 7, no. S1, pp. S348-354, 2014.

[11] Wei, P., et al., "A systematic review of soy isoflavone supplements on osteoporosis in women," Asian Pac J Trop Med., vol. 5, no. 3, pp. 243-8, 2012.

[12] Govindarajan, M., "Chemical composition and larvicidal activity of leaf essential oil from Clausena anisata (Willd.) Hook. f. ex Benth (Rutaceae) against three mosquito species," Asian Pac J Trop Med., vol. 3, no. 11, pp. 874-877, 2010.

[13] Salem, M.Z.M, et al., "Evaluation of extracts and essential oil from callistemon viminalis leaves antibacterial and antioxidant activities, total phenolic and flavonoid contents," Asian Pac J Trop Med., vol. 6, no. 10, pp. 785-791, 2013.

[14] Wiwanitkit, S., Wiwanitkit ,V., "Afebrile, asymptomatic and non-thrombocytopenic Zika virus infection: don't miss it!, " Asian Pac J Trop Med., vol. 9, no. 5, pp. 513, 2016.

[15] Santhoshkumar,et al., "Green synthesis of titanium dioxide nanoparticles using Psidium guajava extract and its antibacterial and antioxidant properties," Asian Pac J Trop Med., vol. 7, no. 12, pp. 968-976, 2014.

[16] Asadi-Samani, M., et al., "The chemical composition, botanical characteristic and biological activities of Borago officinalis: A review," Asian Pac J Trop Med., vol. 7, no. S1, pp. S22-28, 2014.

[17] Ding, Y., et al., Measuring Scholarly Impact: Methods and Practice, 2014.

[18] Chai, K.H., Xiao, X,. "Understanding design research: A bibliometric analysis of Design Studies (1996-2010)," Design Studies, vol. 33, no. 1, 2012.

[19] Rashid, H.F., "Bibliometric analysis as a tool in journal evaluation," Ser Libr, vol. 20, no. 2-3, 1991.

[20] Ullah, R., et al., "Top-Cited Articles from Dental Education Journals, 2009 to 2018: A Bibliometric Analysis", Journal of Dental Education, vol., 83, no. 12, pp. 1382-1391, 2019.

[21] Mokhtari, H., "Bibliometric Analysis and Visualization of the Journal of Artificial Societies and Social Simulation (JASSS) between 2000 and 2018," Webology, vol. 16, no. 1, 2019.

[22] Jain, S., et al., "Bibliometric analysis of two journals of community dentistry," journals of community dentistry, vol. 12, no. 4, pp. 256-260, 2014.

[23] Yanbing S., et al., "Bibliometric analysis of Journal of Nursing Management from 1993 to 2018," Journal of Dental Education, vol. 9, 2019.

[24] Miyairi, N., Chang, H.W., "Bibliometric characteristics of highly cited papers from Taiwan, 2000-2009," Scientometrics, vol. 92, no. 1, pp. 197-205, 2012.

[25] Persson, O., "Are highly cited papers more international?," Scientometrics, vol. 83, no. 2, pp. 397-401, 2010.

[26] Abt, H.A., "Do important papers produce high citation counts?," Scientometrics, vol. 48, pp.65-70, 2000.

[27] Anyi, K.W.U,. et al., "Bibliometric studies on single journals: A review," Malaysian J Libr Inf Sci., vol. 14, no. 1, pp. 17-55, 2009.

Int. J. Public Health Sci, Vol. 9, No. 2, June 2020: 129 - 136 